\title{
Clinical Evaluation of the Mechanical Axis Finder (MAF) by Radiologic Scanogram of 100 Consecutive Axis Total Knee Replacements
}

\author{
Rupesh Man Sherchan, Arlan Troncillo and Ramon B Gustilo* \\ Gustilo Clinic Ambulatory Surgery Center, Manapla, Negros Occidental, Philippines
}

ISSN: 2576-8875

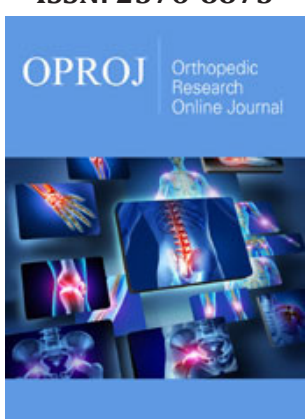

*Corresponding author: Ramon B Gustilo, Gustilo Clinic Ambulatory Surgery Center, Manapla, Negros Occidental, Philippines

Submission: 蛊 February 06, 2020

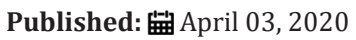

Volume 7 - Issue 1

How to cite this article: Rupesh Man S, Arlan T, Ramon B G. Clinical Evaluation of the Mechanical Axis Finder (MAF) by Radiologic Scanogram of 100 Consecutive Axis Total Knee Replacements. Ortho Res Online J. 7(1). OPROJ.000653.2020. DOI: 10.31031/OPROJ.2020.07.000653

Copyright@: Ramon B Gustilo, This article is distributed under the terms of the Creative Commons Attribution 4.0 International License, which permits unrestricted use and redistribution provided that the original author and source are credited.

\begin{abstract}
The use of Mechanical Axis Finder (MAF) is reliable in achieving the correct mechanical axis in (93.3\%) out of 100 consecutive Axis Knee System Surgeries. Correct mechanical Axis is defined as 0 degrees(neutral) +-3 degrees. The rest (6.7\%) fell 4-7 degrees of varus or 8-9 degrees valgus. Post-operative scanograms (hip-knee-ankle) were obtained in all 100 knees, 2-3 months after surgery. Patello-femoral tracking based on patella lateral displacements on Laurin patellar x-ray view, eighty nine percent exhibited normal or minimal lateral displacement. There was no patellar dislocation. All bone preparations of both femur and tibia were performed using extramedullary method. The preoperative knee society pain score improved from 49.59 to 88.95 at 2-3 months follow up. The patient satisfaction rate, average score was $87.8 \%$. Complications consisted of 2 infection, 2 aseptic femoral loosening requiring revision and two knee stiffness. With the use of the Axis Knee System, the cost of TKA in the Philippines is markedly reduced by $100-200 \%$.
\end{abstract}

\section{Introduction}

Proper alignment of the knee is considered to be one of the most determinant factors in determining the long-term outcomes after total knee arthroplasty, and correct mechanical axis alignment decrease both the mechanical and shear stresses placed on the bearing surfaces, as well as the bone/prosthesis interfaces [1-3]. In addition, proper alignment aids to balance the forces transmitted through the soft-tissue envelope, which is crucial for suitable functioning of the joint. Furthermore, when total knee arthroplasties are poorly aligned this can result in decreased implant survivorship, as well as being implicated as a cause for increased wear, poor functional outcomes, and early failure leading to component loosening. Total Knee Replacement is the most common joint replacement done and most expensive as well worldwide. Axis Total Knee System is a joint venture between the Department of Science and Technology (DOST) Philippines and Orthopedic International Inc. Philippines to provide affordable and quality total knee systems for Asians and in particular for the Philippines.

\section{Mechanical Axis Finder (MAF)}

Principle: Mechanical Axis Finder (MAF) is an extra-medullary device use to determine mechanical axis to the femur of each patient. Any point on the knee will trace a sphere centered on the femoral head when the knee is moved to different positions. Three points on a sphere will define a circle on the sphere. A reference line drawn through the center of the circle and perpendicular to the circle will pass through the center of the sphere. The MAF is a device that records the positions of 3 points in space. The three points identified by the MAF are used to locate the center of the femoral head. The position of the second pin is compensated so that it is perpendicular to the mechanical axis. The 2 pins are collinear with the mechanical axis when viewed in the coronal plane.

\section{Method and Materials}

This is both a retrospective and continual prospective study. Retrospective study group from January 2015 to December 2018 consists of 49 patients, (69 knees) with standard knee X-ray pre-op and Hip-Knee-Ankle scanogram post-op after 2 months. The prospective 
study group starting from January 2019 onwards consists of 21 patients, (31 knees) with both pre-op and post-op HKA scanogram. From 2015 to 2019 a total of 70 patient with 100 arthritic knees underwent total knee replacement using Axis Knee System with Femoral Mechanical Axis Finder. Patients with previous corrective osteotomies in femur or tibia were excluded from this study. All patients in this study were classified into 4 categories (A, B, C, D) upon registration depending on their ability to pay. 'A' are completely private patients with Phil-health, HMO Insurances and able to pay any hospital and professional charges. ' $\mathrm{B}$ ' has Phil-health, HMO Insurances, and relatives. ' $\mathrm{C}$ ' has Phil-health with relatives helping and ' $\mathrm{D}$ ' completely indigent patient- no Phil-health, no other sources of income.

Percentages of distribution based on their ability to pay A (45pats)-64\%, B (11pats)-16\%, C (14pats)-20\%, D-0\%. All patient were from Gustilo Clinic Ambulatory Surgery Center. Patient data were gathered from Gustilo Mobile Medical Record System (GMMR). Surgery was done by main surgeon Dr. Ramon B Gustilo and his assistant fellow Surgeons in training. Preoperatively, in all patients AP pelvis, AP/Lat $(0,20 \mathrm{deg})$ standing and Laurin view knee $\mathrm{x}$-rays were taken and was archived in PACS. For the prospective study group patient additional HKA scanogram was taken compulsorily. Patient is made to stand on the platform, equal weight bearing on both legs with patella at the center and facing forward. Using Quantum Medical Imaging X-ray machine and Fujifilm CR system, $\mathrm{X}$-ray plate 40x $14 \mathrm{inch}$. X-ray beam is projected from a distance of 79inch at 70-75KVP (varies to the patient thickness), 150/200MA, 20-40MAS. Image is processed in Fujifilm CR system and archived in K-PACS which is accessible at the orthopedic clinic.

Immediate after surgery postop $\mathrm{x}$-ray of the knees were taken at the recovery room and standing HKA scanogram were taken 2 months after. Then patients were followed up every 6 months, 1 year and 2 yearly.

Using Hip- knee -ankle scanogram radiograph, corrected mechanical axis alignment was measured. Using lateral knee X-ray femoral and tibial component alignment was measured and using the skyline view the patellar tracking was measured. The femoral mechanical axis angle (FMA), Mechanical axis deviation angle (MAD) and the distance of Mechanical axis deviation ( $\mathrm{mm}$ ) from the center of the knee were all measured as showed in the Figure1-3.

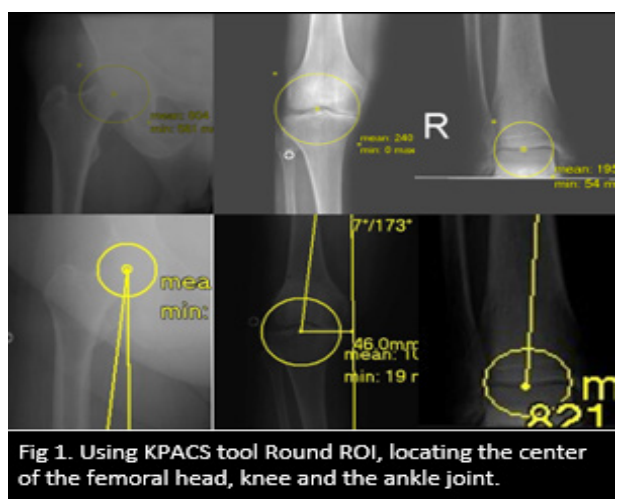

Figure 1: Using KPACS tool round ROI, locating the center of the femoral head, knee and ankle joint.

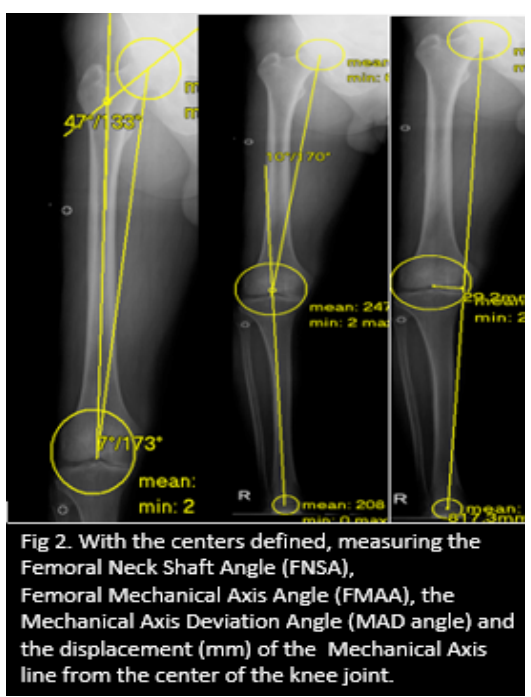

Figure 2: With the centers defined, measurement of the Femoral Neck Shaft Angle (FNSA), Femoral Mechanical Axis Angle (FMAA), Mechanical Axis Deviation angle (MAD) and the displacement (mm) of the mechanical axis line from the center of the knee joint. 


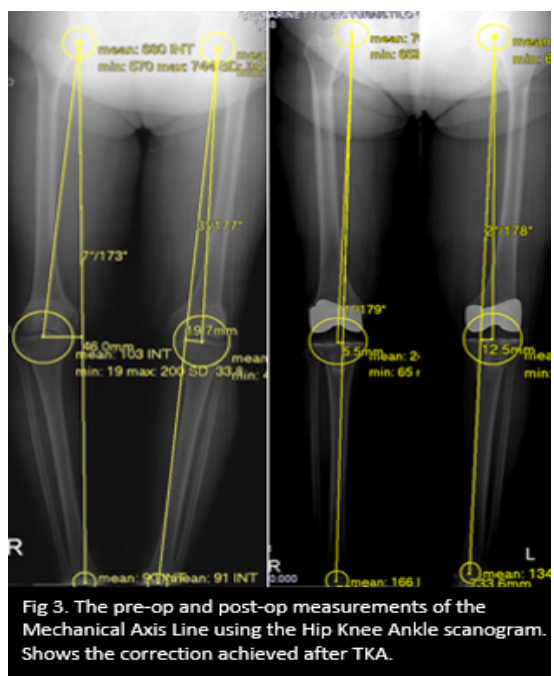

Figure 3: The pre-op and post-op measurements of the Mechanical axis line using the hip knee ankle scanogram. Shows the correction achieved after TKA.

There were 20 male (29\%) and 50 females (71\%) in this study. Patient age were from 28-89yrs and average of 68yrs. Patients BMI measured from 22-49 and average of 28.2 (overweight). 69 knees with varus deformity (69\%) and 31 knees with a valgus deformity (31\%). Preoperative varus deformity ranging from 6-33 degree and valgus deformity ranging from 8-20degrees. There were 24 knees with flexion contracture ranging from 5-40degree. There were 41 unilateral knee patients (58.5\%) and 29 bilateral knee patients (41.5\%). Among the bilateral knee replacement patients, 25 patients underwent single stage procedure $(86 \%)$ while 4 patients underwent 2 staged procedure (14\%) [Table 1-4].

Table 1: Patients demographics.

\begin{tabular}{|c|c|c|c|}
\hline Patients & $\mathrm{n}=70$ & Knees & $\mathrm{n}=100$ \\
\hline Male & $n=20(29 \%)$ & Laterality & $\begin{array}{l}R=49 \\
L=51\end{array}$ \\
\hline Female & $\mathrm{n}=50(71 \%)$ & & \\
\hline Age & $\begin{array}{l}28-89 y r s \\
\text { avg 68yrs }\end{array}$ & & \\
\hline BMI & $\begin{array}{c}\text { 22-49 } \\
\text { avg28.2 } \\
\text { overweight }\end{array}$ & & \\
\hline $\begin{array}{c}\text { Duration of Symp- } \\
\text { toms }\end{array}$ & 2 months - 30yrs & & \\
\hline
\end{tabular}

Table 2: Diagnosis.

\begin{tabular}{|c|c|c|}
\hline Causes of Arthritis & Cases & Percentage \\
\hline Degenerative & 61 & $87 \%$ \\
\hline Rheumatoid & 9 & $13 \%$ \\
\hline
\end{tabular}

Table 3: Grade of arthritis (Kellgren Lawrence).

\begin{tabular}{|c|c|}
\hline Grade I & - \\
\hline Grade II & $6 \%$ \\
\hline Grade III & $50 \%$ \\
\hline Grade IV & $44 \%$ \\
\hline
\end{tabular}

Table 4: Knee deformities.

\begin{tabular}{|c|c|c|c|c|}
\hline Coronal/ Sagittal & Patient & Knee & $\%$ & $\begin{array}{c}\text { Severity of Defor- } \\
\text { mities }\end{array}$ \\
\hline Varus Knee & 46 & 69 & $69 \%$ & 6-33deg \\
\hline Valgus Knee & 24 & 31 & $31 \%$ & 8-20deg \\
\hline $\begin{array}{c}\text { Flexion Contrac- } \\
\text { ture }\end{array}$ & 20 & 24 & $\%$ & 5-40deg \\
\hline Recurvatum & 2 & 2 & $\%$ & 10deg \\
\hline
\end{tabular}

\section{Surgical technique}

All patient surgery was done under spinal anesthesia. The prospective study group patient received an additional intraarticular and intra-muscular cocktail of (Bupivacaine/Ketorolac/ Epinephrine/Clonidine) analgesia. These surgical steps were followed.

Step 1. Expose the knee. A standard medial para-patellar incision is made.

Step 2. Insert the pin holder with the FMAF Pin in the center locator sleeve. Align FMAF Pin marking to pointers 1, 2 and 3. Drill the threaded second pin into place.

Step 3. Connect the Tibial MAF to the 2-femur pin and define the Tibial Mechanical Axis. Perform soft tissue release. Release the M/L ligaments to align the Tibial Mechanical Axis with the Femoral Mechanical Axis. Then place the 2 pins on the tibia through the guide holes in the Tibial MAF.

Step 4. Size the femur and apply the cutting blocks. Then add the tibial cutting block.

Step 5. Match the femur on the tibia.

Apply the jack until the collateral ligaments are taut and the femur is set to its correct rotation.

Step 6. Cut the femur (distal cut) advance the femur APCB on the cut surface. 
Do the anterior and posterior cuts.

Step 7. Determine the tibial implant thickness and cut the proximal tibia.

Apply the tibial stylus on the TCB and point it on the defect. Cut the proximal tibia. Apply the correct-size tibia drill guide.

Step 8. Apply the trial components and do additional releases to fine tune balancing.

Fix tibial rotation then punch for the keel.

Step 9. Cement the implants. (Table 5 \& 6)

Table 5:

\begin{tabular}{|c|c|c|}
\hline Surgical Procedure & Nos. & Percentage \\
\hline Unilateral TKA & 41 & $58.50 \%$ \\
\hline Bilateral TKA & 29 & $41.50 \%$ \\
\hline Single stage Bilateral TKA & 25 & $86 \%$ \\
\hline 2 staged Bilateral TKA & 4 & $14 \%$ \\
\hline
\end{tabular}

Table 6: Intra OP data.

\begin{tabular}{|c|c|c|}
\hline Approach & $\begin{array}{c}\text { Medial para-patellar } \\
\text { Sub-vastus } \\
\text { Quadriceps snips } \\
\text { Quadriceps splitting }\end{array}$ & $\begin{array}{c}83 \\
17 \\
8 \\
3\end{array}$ \\
\hline Lateral Release & $\begin{array}{c}\text { Released } \\
\text { No Release }\end{array}$ & $\begin{array}{l}45 \\
55\end{array}$ \\
\hline Operation Time & $\begin{array}{l}\text { Unilateral knee } \\
\text { Bilateral knee }\end{array}$ & $\begin{array}{l}\text { 60-180min } \\
140-300 \mathrm{~min}\end{array}$ \\
\hline \multirow[t]{3}{*}{ Implant Size } & $\begin{array}{c}\text { Femoral component } \\
2 \mathrm{~N}, 3 \mathrm{~N}, 4 \mathrm{~N}, 5 \mathrm{~N}\end{array}$ & $3 \mathrm{~N}, 4 \mathrm{~N}$ \\
\hline & $\begin{array}{c}\text { Tibial Component } \\
\text { 2N,3N,4N,5N/4W,5W }\end{array}$ & $3 \mathrm{~N}, 4 \mathrm{~N}$ \\
\hline & $\begin{array}{l}\text { Patellar Component } \\
\qquad \begin{array}{c}(\mathrm{n}=9) \\
26 \mathrm{~mm} \\
29 \mathrm{~mm}\end{array}\end{array}$ & $\begin{array}{l}7 \\
8\end{array}$ \\
\hline
\end{tabular}

\section{Radiographic measurements}

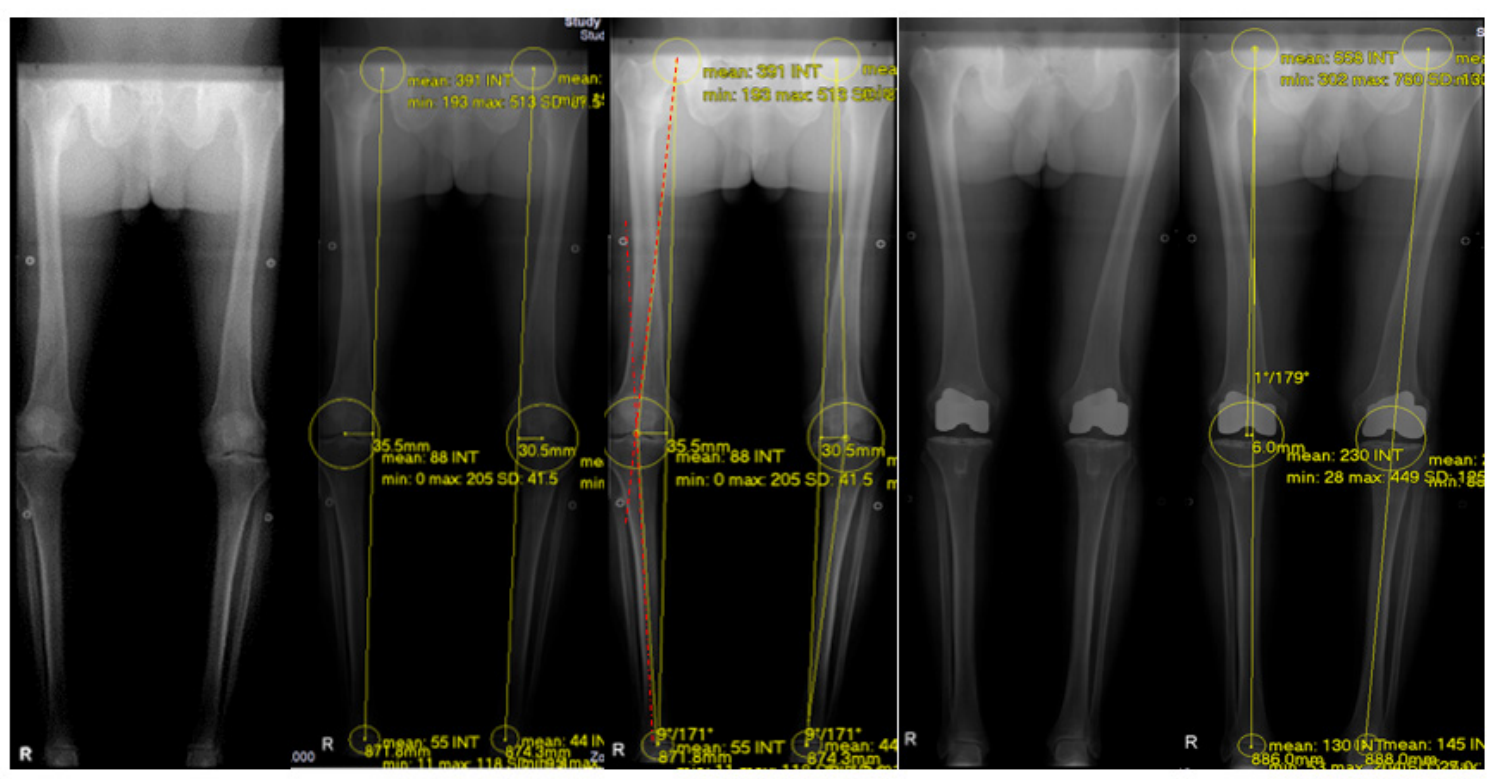

Figure 4: The pre-op and post-op measurements of the Mechanical axis line using the Hip Knee Ankle scanogram.

The dotted red line denotes the Mechanical Axis Deviation Angle (MAD).

On the Hip Knee Ankle scanogram, a straight line is drawn from the center of the femoral head to the center of the ankle. This line is away from the center of the knee and this distance ( $\mathrm{mm}$ ) is measured in both varus and valgus knees. Also, the degree of deviation of this line, from the center of the knee is measured and categorized as Neutral if it passed through the center, or varus and valgus outlier. The degree of correction, or the accuracy of the FMA finder is then measured 2 months after Axis Total Knee Replacement in standing HKA scanogram, measuring how close the line was to the center of the knee. Our goal is to bring the line in neutral or within the 3 degrees of varus and valgus outliers. Similarly, the preoperative mechanical axis deviation angle (MAD) was compared to the postoperative MAD to measure the degree of deformity correction. Mechanical axis deviation angle was measured using the center of the femoral head to the center of the knee and center of the tibial spine to the center of the ankle joint (using the femoral and tibial mechanical axis line). Implant position either in flexion or extension was measured in lateral view and patellar tracking was measured in Laurin view. Measurement was done by two individual orthopedic surgeons in fellowship training. The author was one of the readers (Reader 1) and measurement was repeated every 2 months after to look at the intra-observer reliability (Figure 4; Table 7-10). 
Table 7:

\begin{tabular}{|c|c|c|c|c|c|}
\hline & $\begin{array}{c}\text { Femoral Neck } \\
\text { Shaft Angle } \\
\text { FNSA }\end{array}$ & $\begin{array}{c}\text { Femoral Mechan- } \\
\text { ical Axis Angle } \\
\text { FMAA }\end{array}$ & $\begin{array}{c}\text { Mechanical Axis Deviation } \\
\text { Angle MAD } \\
\text { (pre-op) }\end{array}$ & $\begin{array}{c}\text { Anatomical Tibiofemoral } \\
\text { Angle } \\
\text { aTFA (pre-op) } \\
\text { Standard X-ray }\end{array}$ & $\begin{array}{c}\text { Anatomical Tibiofemoral } \\
\text { Angle } \\
\text { aTFA (post op) } \\
\text { HKA Scanogram }\end{array}$ \\
\hline Maximum & $159 \mathrm{deg}$ & $8 \mathrm{deg}$ & 22deg valgus & $28 \mathrm{deg}$ valgus & $13 \mathrm{deg}$ valgus \\
\hline Minimum & $111 \mathrm{deg}$ & $4 \mathrm{deg}$ & $33 \mathrm{deg}$ varus & $20 \mathrm{deg}$ varus & $7 \mathrm{deg}$ varus \\
\hline Mean & $132.2 \mathrm{deg}$ & $5.5 \mathrm{deg}$ & $5.65 \mathrm{deg}$ varus & $1 \mathrm{deg}$ valgus & $3.4 \mathrm{deg}$ valgus \\
\hline SD & 7.57 & 0.93 & 9.97 & 7.8 & 4.7 \\
\hline
\end{tabular}

Table 8: Measurements by Reader 1 and Reader 2, two months, post Total Knee Replacement (AXIS KNEE SYSTEM) using Hip- Knee- Ankle scanogram.

\begin{tabular}{|c|c|c|c|c|c|c|}
\hline & \multicolumn{3}{|c|}{ Reader 1} & \multicolumn{3}{|c|}{ Reader 2} \\
\hline & $\begin{array}{l}\text { Mechanical Axis } \\
\text { line away from } \\
\text { the knee center } \\
(\mathrm{mm})\end{array}$ & $\begin{array}{c}\text { Mechanical Axis } \\
\text { Deviation Angle } \\
\text { MAD (degree) }\end{array}$ & $\begin{array}{l}\text { Mechanical Axis } \\
\text { line outliers. }\end{array}$ & $\begin{array}{l}\text { Mechanical Axis } \\
\text { line away from the } \\
\text { knee center (mm) }\end{array}$ & $\begin{array}{c}\text { Mechanical Axis } \\
\text { Deviation Angle } \\
\text { MAD (degree) }\end{array}$ & $\begin{array}{l}\text { Mechanical Axis } \\
\text { line outliers. }\end{array}$ \\
\hline Maximum & $47 \mathrm{~mm}$ & 8deg valgus & 3 deg valgus & $41.5 \mathrm{~mm}$ & 9deg valgus & 4deg valgus \\
\hline Minimum & 0 & $15 \mathrm{deg}$ varus & $6 \mathrm{deg}$ varus & 0 & $13 \mathrm{deg}$ varus & $6 \mathrm{deg}$ varus \\
\hline Mean & $11.98 \mathrm{~mm}$ & $2.26 \mathrm{deg}$ varus & $0.83 \mathrm{deg}$ varus & $11.85 \mathrm{~mm}$ & $1.73 \mathrm{deg}$ varus & $0.78 \mathrm{deg}$ varus \\
\hline SD & 11.02 & 4.85 & 1.92 & 9.82 & 4.61 & 2.04 \\
\hline
\end{tabular}

Table 9: Knee Society Score clinical and functional used to measure the functional outcome of the patient following the Total Knee Replacement

\begin{tabular}{|c|c|c|c|c|c|}
\hline & \multicolumn{2}{|c|}{ Pre-Operative } & \multicolumn{2}{c|}{ Post-Operative } & $\begin{array}{c}\text { Rate } \\
\text { Patient } \\
\text { Satisfaction } \\
\end{array}$ \\
\hline & KSS Pain & KSS Function & KSS Pain & KSS Function & \\
\hline Highest Score & 80 & 99 & 100 & 100 & $98 \%$ \\
\hline Lowest Score & 10 & 88 & 55 & 91 & $80 \%$ \\
\hline Mean & 49.59 & 94.17 & 88.95 & 97.4 & $87.80 \%$ \\
\hline SD & 16.9 & 3.1 & 10.9 & 2.04 & \\
\hline
\end{tabular}

Table 10:

\begin{tabular}{|c|c|c|c|}
\hline & Operation Time & Tourniquet Time & Blood Loss \\
\hline Maximum & $300 \mathrm{~min}$ & $200 \mathrm{~min}$ & $500 \mathrm{ml}$ \\
\hline Minimum & $60 \mathrm{~min}$ & $50 \mathrm{~min}$ & $50 \mathrm{ml}$ \\
\hline Average & $136 \mathrm{~min}$ & $107.6 \mathrm{~min}$ & $202 \mathrm{ml}$ \\
\hline SD & 46.1 & 28.9 & 113.9 \\
\hline
\end{tabular}

\section{Functional outcome}

Functional outcome was measured by comparing pre- operative and postoperative Knee Society Score clinical and functional. We also added patient's satisfaction rating to our overall outcome. Post-surgical complications, hospital stay, and revision rate were also included in our study (Figure 5-8). 


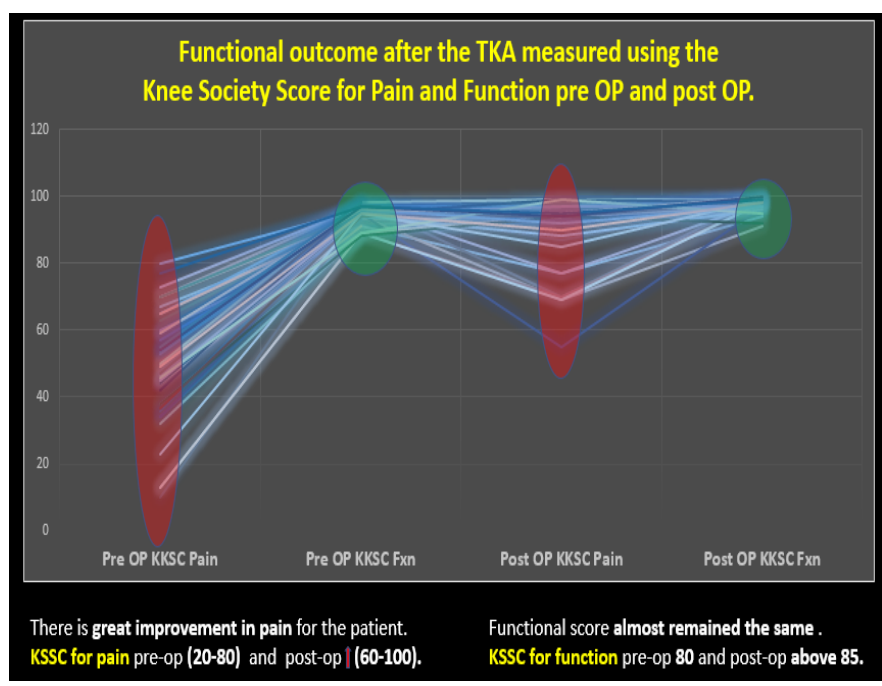

Figure 5: Functional outcome KSS pain and functional represented in graph.

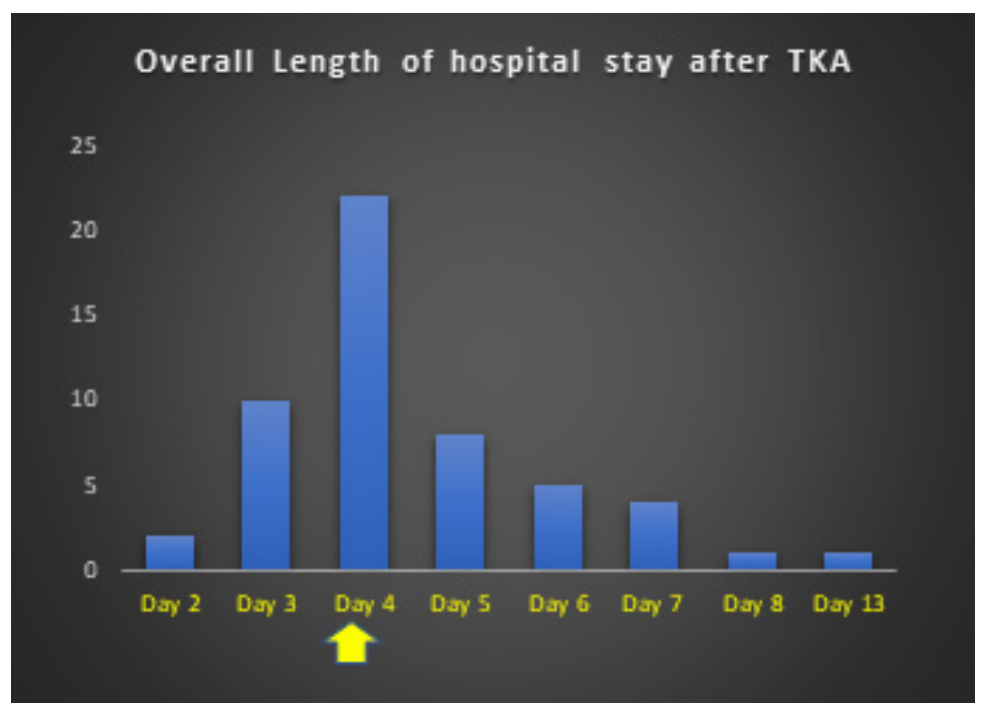

Figure 6: Overall hospital stay after total knee replacement.

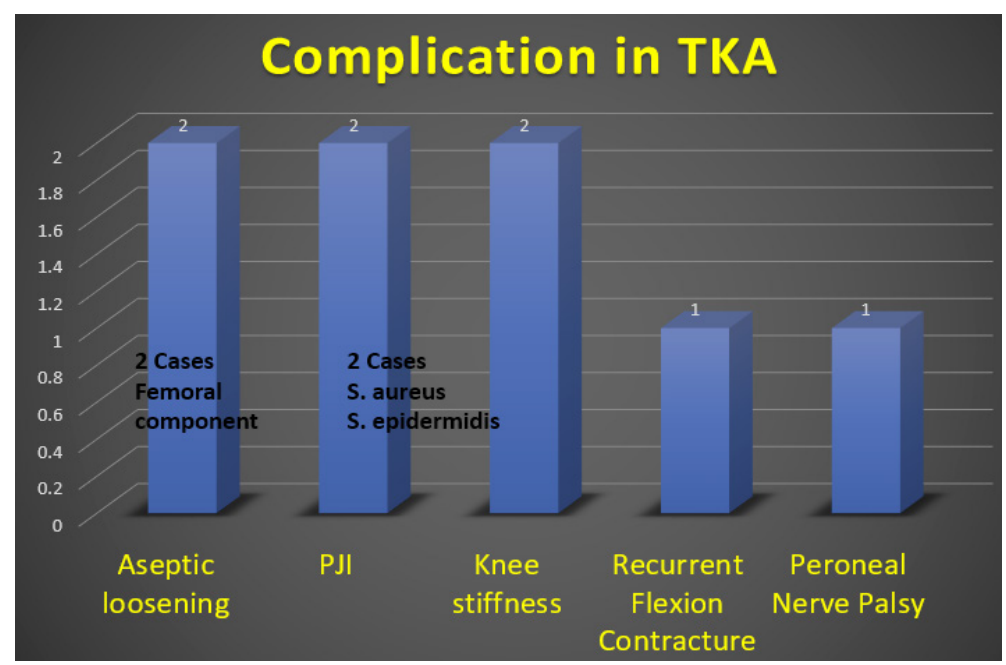

Figure 7: Complication after total knee replacement. 


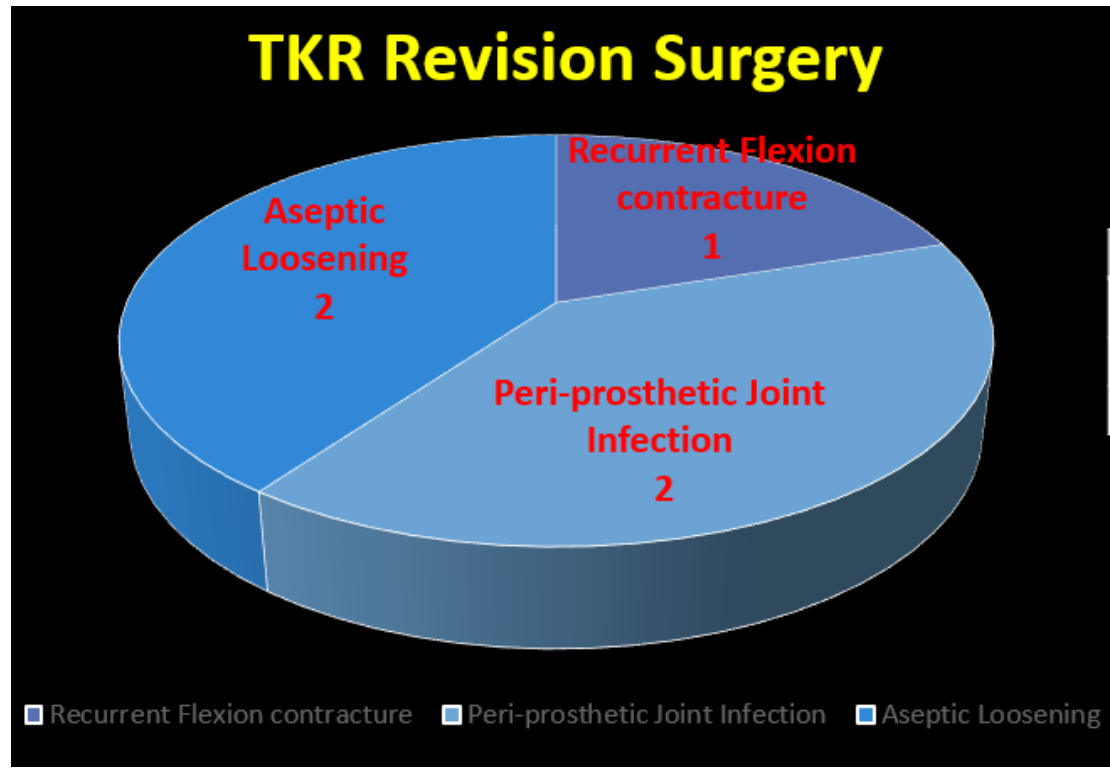

Figure 8: Revision surgery after total knee replacement.

\section{Result}

\section{Clinical correction}

In our study, the patient with severe valgus deformity of $22 \mathrm{deg}$ and varus deformity of 33deg was corrected to $8 \mathrm{deg}$ valgus and $13 \mathrm{deg}$ varus respectively. Post-operative correction of mechanical axis deviation angle was with the mean value of $2.26 \mathrm{deg}$ varus. Whereas the postoperative correction of anatomic tibio-femoral angle was with the mean value of $3.4 \mathrm{deg}$ valgus. Clinical results of patella-femoral tracking showed no dislocation.

\section{Radiological correction}

Using mechanical axis finder (MAF), 55.5\% of the knees were corrected within 3 degree of varus, $20 \%$ in neutral and $17.7 \%$ within 3 degree of valgus alignment. Hence overall $93.3 \%$ of the knees were corrected within +/- 3 degree of neutral alignment. The remaining $6.7 \%$ fell outside between 3 to 6 degree of varus alignment.

Among the $55.5 \%$ of the corrected knees within 3 degree of varus alignment, majority of them fell within 1 degree of varus showing that the trend is towards neutral alignment (Figure 9-11; Table 11). Radiologic evaluation of patella femoral tracking with Laurin views showed 78\% in normal alignment and 22\% with less than $25 \%$ displacement. Comparing medial para-patellar to subvastus approach, the sub-vastus approach showed better patellofemoral tracking with $91 \%$ in grade I alignment.

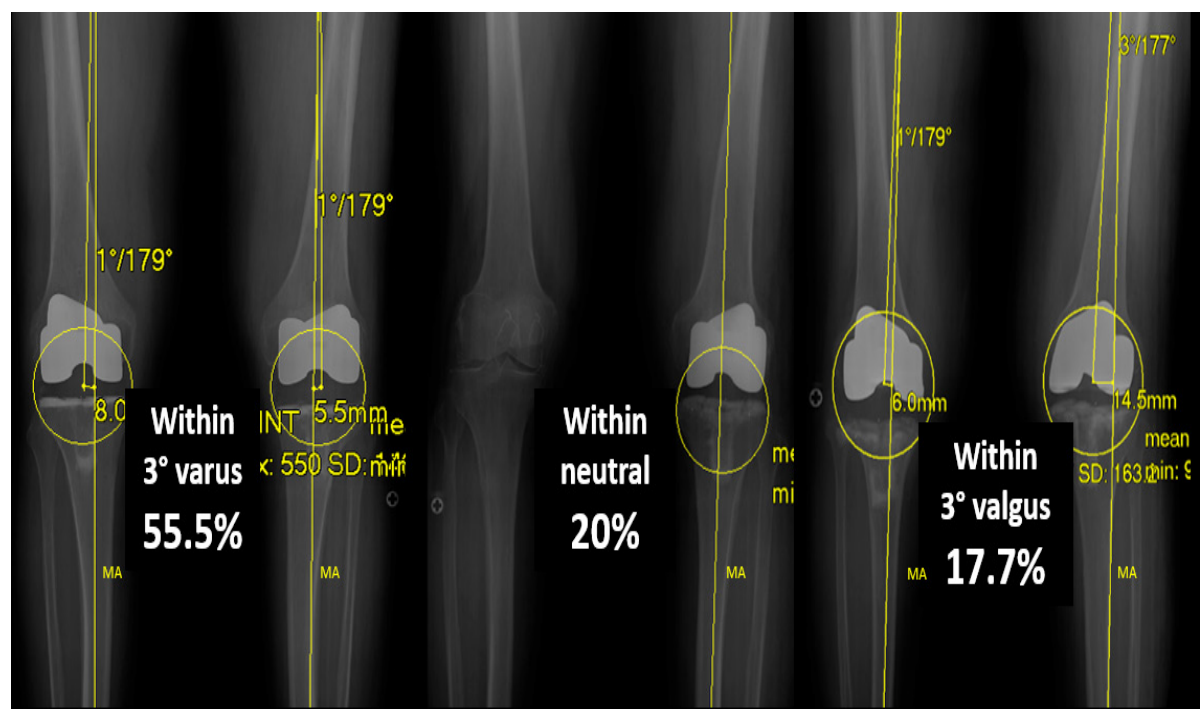

Figure 9: Overall, 93.3\% of the knees are within +/- 3 degree of neutral mechanical axis alignment using FMAF. 


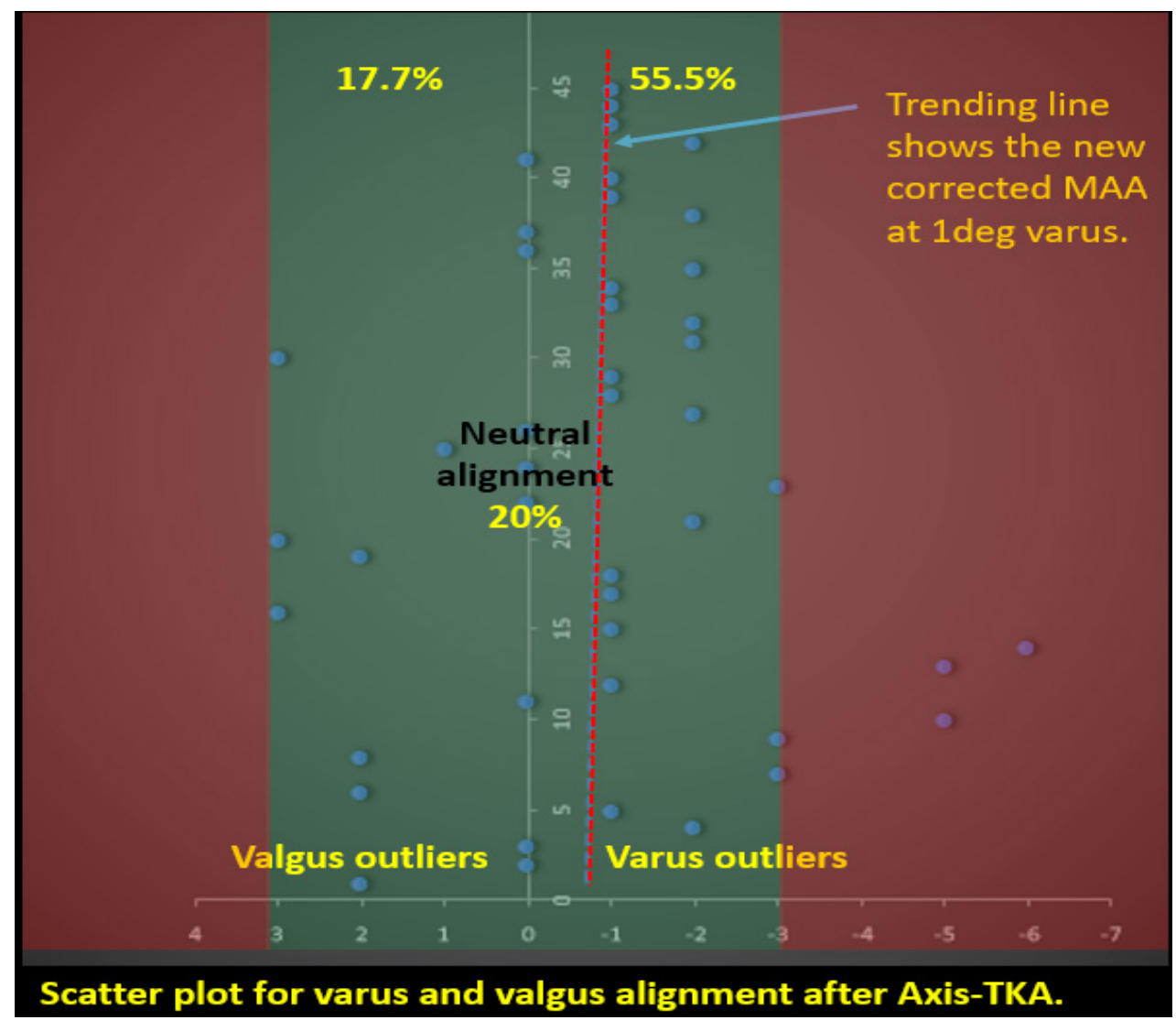

Figure 10: Showing new mechanical axis trending line within 1 degree of varus.
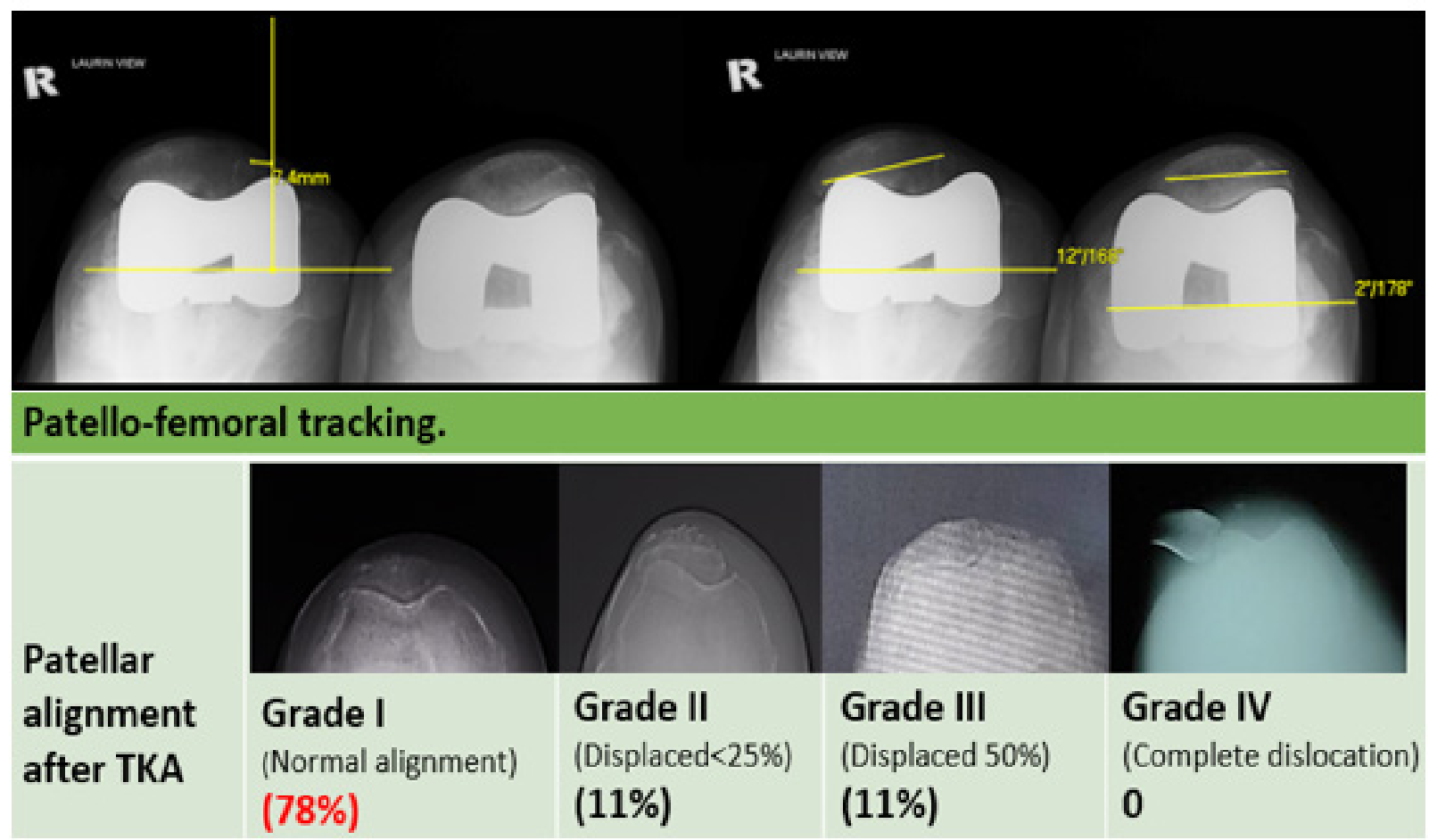

Figure 11: Measurement of patello-femoral tracking. 
Table 11: Patello-femoral tracking after total knee replacement.

\begin{tabular}{|c|c|c|}
\hline Patellar Alignment & \multicolumn{2}{|l|}{} \\
\hline Grade I & $78 \%$ & $\begin{array}{c}\text { 91\% of Sub-vastus } \\
80 \% \text { of Medial para-patellar }\end{array}$ \\
\hline Grade II & $11 \%$ & \\
\hline Grade III & $11 \%$ & (no dislocation) \\
\hline Grade IV & 0 & Avg 7.2deg \\
\hline Patellar Tilt & $1-25 \mathrm{deg}$ & Pie crust technique \\
\hline Lateral Release & $46 \%$ & \\
\hline
\end{tabular}

\section{Functional results}

In 2 months follow up the preoperative KSS pain score improved from 49.59 to 88.95 . Whereas the KSS functional score showed minor improvement from 94.1 to 97.4 . However, the patient satisfaction rate was above $80 \%$ and reached $87.8 \%$.

Complication at 5 years period was $8 \%$. We had 2 cases of infection, 2 cases of aseptic loosening of femoral component (1-trauma, 1-malpositioning), 2 cases of knee stiffness,1 case of flexion contracture (inadequate release of the posterior capsule) and 1 case of peroneal nerve palsy (severe valgus knee).

Revision at 5 years period was $5 \%$.

\section{Discussion}

Native knee alignment varies throughout the population, and neutral mechanical alignment, defined as $0^{\circ}$, is not always observed in healthy, non-arthritic patients [4]. Hsu et al. [5] found the hipknee-ankle angle (HKA) of normal adults was actually $1.2^{\circ}$ of varus and only $2.2 \%$ had a HKA of $0^{\circ}$. Fahlman et al. [6] found only $11 \%$ of 143 patients had bilateral mechanically neutral knees, with $49 \%$ aligned in mechanical varus, and $22 \%$ aligned in mechanical valgus. In asymptomatic adults, constitutionally varus knees (HKA $>3^{\circ}$ varus) has been found in up to $32 \%$ of men and $17 \%$ of women [7] Conversely, in a population of symptomatic osteoarthritic patients, $71 \%$ had varus alignment with a mean HKA of $-9.0^{\circ}$ [8]. Vandekerckhove et al. [9], have shown that constitutional varus does contribute to a higher incidence of osteoarthritis in the general population. Coronal alignment is considered an important variable in attaining a well-functioning TKA [10-12].

Proper alignment improves soft tissue balance and decreases mechanical and shear stresses placed on the implant fixation interface as well as on articular bearing surfaces [1-3]. Malalignment results in decreased functional outcomes and survivorship and has been implicated as a cause of early failure due to wear and loosening $[3,11,13-16]$, particularly in older implants of non-highly crosslinked polyethylene. Most surgeons follow the tenet that postoperative alignment should be within $3^{\circ}$ of a neutral mechanical axis [1-4,15,17-20]. Mechanical alignment is performed by cutting both the femur and tibia perpendicular to their respective mechanical axes [21]. This results in a TKA femoral-tibial angle of approximately $5^{\circ}-7^{\circ}$ of valgus with the purpose of creating even load distribution across the joint [22]. Advocates of mechanical alignment feared that anatomic alignment would increase medial loads and risk medial tibial component fixation failure [22]. Restoration of mechanical alignment to $0^{\circ}$ may increase component longevity and has demonstrated a 3\% loosening rate when the mechanical axis crossed the middle $1 / 3^{\text {rd }}$ of the prosthesis versus $24 \%$ when the mechanical axis was shifted medially or laterally [2].

Similarly, Fang et al. [4] found neutral mechanical alignment had a lower failure rate $(0.5 \%)$ than varus $(1.8 \%)$ or valgus $(1.5 \%)$. This is supported in wear analysis of TKA retrievals [2,13,2327]. Comparison between extra-medullary and intra-medullary alignment device showed no significant differences; each system allowed satisfactory alignment [28]. The alignment of the Extramedullary distal femur osteotomy is as accurate as Intra-medullary systems. Furthermore, Extra-medullary distal femur osteotomy without invading the femoral medullary cavity could reduce postoperative bleeding and the transfusion rate [29,30].

BMI may play a role in failure of the tibial component. Berend et al. [15] found a 168 times higher failure rate if the tibia component was positioned in varus $\left(\geq 3^{\circ}\right)$ in conjunction with a BMI $>33.7 \mathrm{~kg} /$ $\mathrm{m}^{2}$. Parratte et al. [25], [8] found no differences in 15 and now 20year survival of mechanically aligned knees $\left(0^{\circ} \pm 3^{\circ}\right)$ versus those marginally outside of these parameters $\left(4^{\circ}-6^{\circ}\right)$. Bonner et al. [31] stratified TKA patients into "aligned" $\left(0^{\circ} \pm 3^{\circ}\right)$ and "malaligned" (deviation $>3^{\circ}$ ) groups and found slightly higher 15-year survival in the aligned group, although the difference was not statistically significant. Matziolis et al. [32] found no outcome differences in TKAs aligned in mechanical varus versus those in neutral. A review of TKAs performed on patients with pre-operative varus gonarthrotic showed no functional difference between TKAs aligned in postoperative mechanical varus versus neutral, as well as no difference in revision rates. Similarly, Hadi et al. [27] did not find increased revision rates of malaligned TKAs measured using the mechanical axis but did find an association between malalignment and revision rate using an anatomical axis.

Some evidence suggests patients placed in mechanical varus have an increase in satisfaction after TKA. Vanlommel et al. [33] evaluated TKAs in pre-operative varus and found those left in mild mechanical varus $\left(3^{\circ}\right.$ to $\left.6^{\circ}\right)$ had superior post-operative Knee Society (KSS) scores compared to knees corrected to neutral or those left in increased varus $\left(>6^{\circ}\right)$. In the absence of good long-term data most authors would still suggest a neutral mechanical axis still remains the optimal alignment and should be the benchmark against which new alignment targets are measured against.

\section{Cost effectiveness of the axis knee system}

The Average total cost of the Axis Knee System, Unilateral on A, $\mathrm{B}, \mathrm{C}$ and $\mathrm{D}$ patients are as;
A Patients- P400,000.00 (\$8000.00)
B Patients- P300,000.00 (\$6000.00) 


\section{Patients- P250,000.00 (\$5000.00)}

D Patients- P100,000.00 (\$2000.00).

\section{Conclusion}

Use of the mechanical axis finder (MAF), is reliable in determining the correct mechanical axis in Total Knee Arthroplasty (93.3\%). The surgical technique with Axis Knee System, achieving soft tissue balance and correct bone preparation results in satisfactory patellofemoral tracking, without incidence of dislocation. Cost Effectiveness Using the Axis Knee System, A joint venture of Orthopedic International and Department of Science and Technology (DOST) is very effective in reducing cost of total knee procedure in the Philippines by $50-100 \%$ and $200-300 \%$ compared to the western world.

\section{References}

1. D'Lima DD, Hermida JC, Chen PC, Colwell CW (2001) Polyethylene wear and variations in knee kinematics. Clin Orthop Relat Res 392: 124-130.

2. Jeffery RS, Morris RW, Denham RA (1991) Coronal alignment after total knee replacement. J Bone Joint Surg Br 73(5): 709-714.

3. D'Lima DD, Chen PC, Colwell JW (2001) Polyethylene contact stresses, articular congruity and knee alignment. Clin Orthop Relat Res 392: 232238.

4. Fang DM, Ritter MA, Davis KE (2009) Coronal alignment in total knee arthroplasty: Just how important is it? J Arthroplasty 24 (6 suppl): 39-43.

5. Hsu RW, Himeno S, Coventry MB, Chao EY (1990) Normal axial alignment of the lower extremity and load-bearing distribution at the knee. Clin Orthop Relat Res 255: 215-227.

6. Fahlman L, Sangeorzan E, Chheda N, Lambright D (2014) Older adults without radiographic knee osteoarthritis: Knee alignment and knee range of motion. Clin Med Insights Arthritis Musculoskelet Disord 7: $1-11$.

7. Hungerford DS, Krackow KA (1985) Total joint arthroplasty of the knee. Clin Orthop Relat Res 192: 23-33.

8. Victor JMK, Bassens D, Bellemans J, Dhollander AAM, Gursu S, et al. (2013) Constitutional varus does not affect joint line orientation in the coronal plane. Clin Orthop Relat Res 472(1): 98-104.

9. Vandekerckhove PT, Matlovich N, Teeter MG, MacDonald SJ, Howard JL, et al. (2017) The relationship between constitutional alignment and varus osteoarthritis of the knee. Knee Surg Sports Traumatol Arthrosc 25(9): 2873-2879.

10. Schiraldi M, Bonzanini G, Chirillo D, Tullio V (2016) Mechanical and kinematic alignment in total knee arthroplasty. Ann Transl Med 4(7): 130.

11. Cherian JJ, Kapadia BH, Banerjee S, Jauregui JJ, Issa K, et al. (2014) Mechanical, anatomical, and kinematic axis in TKA: Concepts and practical applications. Curr Rev Musculoskelet Med 7(2): 89-95.

12. Barrett WP, Mason JB, Moskal JT, Dalury DF, Oliashirazi A, et al. (2011) Comparison of radiographic alignment of imageless computer-assisted surgery vs conventional instrumentation in primary total knee arthroplasty. J Arthroplasty 26(8): 1273-1284.

13. Oswald MH, Jakob RP, Schneider E, Hoogewoud HM (1993) Radiological analysis of normal axial alignment of femur and tibia in view of total knee arthroplasty. J Arthroplasty 8(4): 419-426.

14. Ensini A, Catani F, Leardini A, Romagnoli M, Giannini S (2007)
Alignments and clinical results in conventional and navigated total knee arthroplasty. Clin Orthop Relat Res 457: 156-162.

15. Berend ME, Ritter MA, Meding JB, Faris PM, Keating EM, et al. (2004) The Chetranjan ranawat award: Tibial component failure mechanisms in total knee arthroplasty. Clin Orthop Relat Res 428: 26-34.

16. Sikorski JM (2008) Alignment in total knee replacement. J Bone Joint Surg Br 90(9): 1121-1127.

17. Green GV, Berend KR, Berend ME, Glisson RR, Vail TP (2002) The effects of varus tibial alignment on proximal tibial surface strain in total knee arthroplasty: The posteromedial hot spot. J Arthroplasty 17(8): 10331039.

18. Ritter MA, Davis KE, Meding JB, Pierson JL, Berend ME, et al. (2011) The effect of alignment and BMI on failure of total knee replacement. J Bone Joint Surg Am 93(17): 1588-1596.

19. Ritter MA, Faris PM, Keating M, Meding JB (1994) Postoperative alignment of total knee replacement its effect on survival. Clin Orthop Relat Res 299: 153-156.

20. Werner FW, Ayers DC, Maletsky LP, Rullkoetter PJ (2005) The effect of valgus/varus malalignment on load distribution in total knee replacements. J Biomech 38: 349-355.

21. Insall JN, Binazzi R, Soudry M, Mestriner LA (1985) Total knee arthroplasty. Clin Orthop Relat Res 192: 13-22.

22. Morgan SS, Bonshahi A, Pradhan N, Gregory A, Gambhir A, et al. (2008) The influence of postoperative coronal alignment on revision surgery in total knee arthroplasty. Int Orthop 32(5): 639-642.

23. Wasielewski RC, Galante JO, Leighty RM, Natarajan RN, Rosenberg AG (1994) Wear patterns on retrieved polyethylene tibial inserts and their relationship to technical considerations during total knee arthroplasty. Clin Orthop Relat Res 299: 31-43.

24. Choong PF, Dowsey MM, Stoney JD (2009) Does accurate anatomical alignment result in better function and quality of life? comparing conventional and computer-assisted total knee arthroplasty. J Arthroplasty 24(4): 560-569.

25. Parratte S, Pagnano MW, Trousdale RT, Berry DJ (2010) Effect of postoperative mechanical axis alignment on the effect of postoperative mechanical axis alignment on the fifteen-year survival of modern, cemented total knee replacements. J Bone Joint Surg Am 92(12): 21432149.

26. Magnussen RA, Weppe F, Demey G, Servien E, Lustig S (2011) Residual varus alignment does not compromise results of TKAs in patients with preoperative varus. Clin Orthop Relat Res 469(12): 3443-3450.

27. Hadi M, Barlow T, Ahmed I, Dunbar M, Culloch P, et al. (2015) Does malalignment affect revision rate in total knee replacements: A systematic review of the literature. Springerplus 4: 835.

28. Ishii Y, Ohmori G, Bechtold JE, Gustilo RB (1995) Extramedullary versus intramedullary alignment guides in total knee arthroplasty. Clin Orthop Relat Res 318: 167-175.

29. Quin YF, Li N, Shi YX, Sun K, Li ZJ (2018) Intramedullary versus extramedullary alignment guides on total knee arthroplasty: A metaanalysis. J Comp Eff Res 7(12): 1181-1193.

30. Tang Q Shang P, Zheng G, Zi Xu H, Liu HX (2017) Extramedullary versus Intramedullary femoral alignment technique in total knee arthroplasty: A meta-analysis of randomized controlled trials. J Orthop Surg Res 12(1): 82.

31. Bonner TJ, Eardley WP, Patterson P, Gregg PJ (2011) The effect of postoperative mechanical axis alignment on the survival of primary total knee replacements after a follow-up of 15 years. J Bone Joint Surg Br 93(9): 1217-1222. 
32. Matziolis G, Krocker D, Weiss U, Tohtz S, Perka C (2007) A prospective, randomized study of computer-assisted and conventional total knee arthroplasty. Three dimensional evaluation of implant alignment and rotation. J Bone Joint Surg Am 89(2): 236-243.
33. Vanlommel L, Vanlommel J, Claes S, Bellemans J (2013) Slight under correction following total knee arthroplasty results in superior clinical outcomes in varus knees. Knee Surgery, Sport Traumatol Arthrosc 21(10): 2325-2330.

For possible submissions Click below: 